\title{
SISTEM INFORMASI CUSTOMER RELATIONSHIP MANAGEMENT PADA PT. ANEKA SUSU
}

\author{
Mas Ayoe Elhias Nst \\ Universitas Potensi Utama \\ Jl. K.L. Yos Sudarso Km. 6.5 No.3-A,Medan \\ Email :masayoe02@gmail.com
}

\begin{abstract}
Abstrak
Pada saat sekarang ini sebagian besar perusahaan Retail masih menggunakan komunikasi secara langsungdan mencatat hasil transaksi dan pengolahan datanya masih dalam bentuk pengolahan data customer sehingga dengan sistem yang lama dapat memerlukan waktu yang relatif lama dan lambat. Pada sistem lama perusahaan masih menggunakan sistem pengolahan data dengan menggunakan sistem berupa microsoft excel maupun microsof word oleh sebab itu tidak dapat melakukan hubungan secara terus-menerus kepada pelanggan. Hal ini menimbulkan masalah dikarenakan pelanggan tidak dapat membantu pemasaran produk yang dimiliki perusahaan, dan akhirnya terjadi penurunan penghasilan dari perusahan.Selain itu juga dengan perkembangan teknologi yang semakin pesat saat ini dalam persaingan bisnis muncul permintaan pelanggan yang bermacam-macam serta kualitas dan pelayanan yang diberikan suatu perusahaan kepada pelanggan. Oleh sebab itu perusahaan menerapkan metode CRM. Metode Customer Relationship Management merupakan suatu metode untuk menarik pelanggan baru agar membeli produk perusahaan dan juga mempertahankan pelanggan lama agar tetap membantu proses pemasaran terhadap produk-produk perusahaan. Dengan penggunaan sistem management pelanggan menggunakan metode Customer Relationship Management (CRM) dapat menarik pelanggan baru dan mempertahankan pelanggan yang telah ada agar dapat membantu setiap proses pemasaran yang dilakukan oleh perusahaan. Peran CRM disini memberikan pengaruh yang sangat besar terhadap tingkat kepuasan pelangga, dengan melayani pelanggan sepenuh hati dan mempertahankan loyalitas pelanggan dengan aplikasi yang bisa diakses dengan mudah.
\end{abstract}

Kata kunci :Sistem informasi, CRM, online system, regresi linier

\begin{abstract}
Abstrak
At the present time the majority of retail companies are still using direct communication and record the results of the transaction and data processing is still in the form of customer data processing so that the old system can require a relatively long time and slow. In the old system the company is still using the data processing system by using a system such as Microsoft Word or Microsoft Excel therefore unable to engage in an ongoing basis to the customer. This poses a problem because the customer cannot help the marketing of the products of the company, and ultimately a decline in income from companies. also with rapid technological developments currently in the business competition emerging customer demand as well as the assortment and quality of services provided a company to the customer. Therefore, companies implement CRM methods. Customer Relationship Management method is a method to attract new customers to buy the company's products and also retain existing customers in order to continue to assist the process of marketing the products of the company. With the use of customer management system using the method of Customer Relationship Management (CRM) can attract new customers and retain existing customers in order to help each of the marketing process undertaken by the company. CRM role here give a very big influence on the level of satisfaction, to serve customers wholeheartedly and maintain customer loyalty with applications that can be accessed easily.
\end{abstract}

Keyword :Information System, CRM, online system, regresi linier 


\section{PENDAHULUAN}

Pelayanan merupakan sesuatu hal yang harus dilakukan dalam sebuah manajemen, guna untuk meningkatkan dan mempertahankan hasil penjualan. Manajemen penjualan merupakansalah satu upaya yang harusdilakukan untuk mendukung dengan memberikan kenyamanan dan rasa kepuasan bagi konsumen pada saat melakukan transaksi pembelian. Tidak semua perusahaan dapat menerapkan sistem aplikasi CRM di pelayanan customer hal ini bisa terjadi akibat banyaknya aspek kepuasan konsumen, atau produk yang dijual merupakan produk unggulan atau banyak diminati oleh para konsumen, sehingga perusahaan tidak memiliki kecemasan atau kekhawatiran akan ditinggalkan oleh konsumen. PT.Aneka Susu adalah perusahaan supplier susu yang melayani transaksi penjualan susu, seberapa besar keuntungan yang dilepaskan begitu saja jika kita tidak mempedulikan kepuasan konsumen. CRM (Customer Relationship Management) merupakan suatu jenis manajemen yang secara khusus membahas teori mengenai penanganan hubungan antara perusahaan dengan pelanggannya dengan tujuan meningkatkan nilai perusahaan di mata para pelanggannya. Tujuan utama dari CRM adalah untuk meningkatkan pertumbuhan jangka panjang dan profitabilitas perusahaan melalui pengertian yang lebih baik terhadap kebiasaan (behavior) pelanggan.Dengan adanya sistem CRM, maka diharapkan agar para pelaku bisnis dapat mengetahui bagaimana langkah langkah atau cara cara melayani konsumen, agar konsumen merasa puas sehingga keuntungan yang diperoleh semakin meningkat, karena apabila konsumen merasa puas dengan pelayanan kita, maka secara otomatis konsumen tersebut akan membeli lagi, atau bahkan menjadi pelanggan tetap bagi bisnis kita.

\section{METODOLOGI PENELITIAN}

Penelitian ini memiliki alur analisis dengan tahap -tahap sebagai berikut seperti Gambar 1. Alur analisis

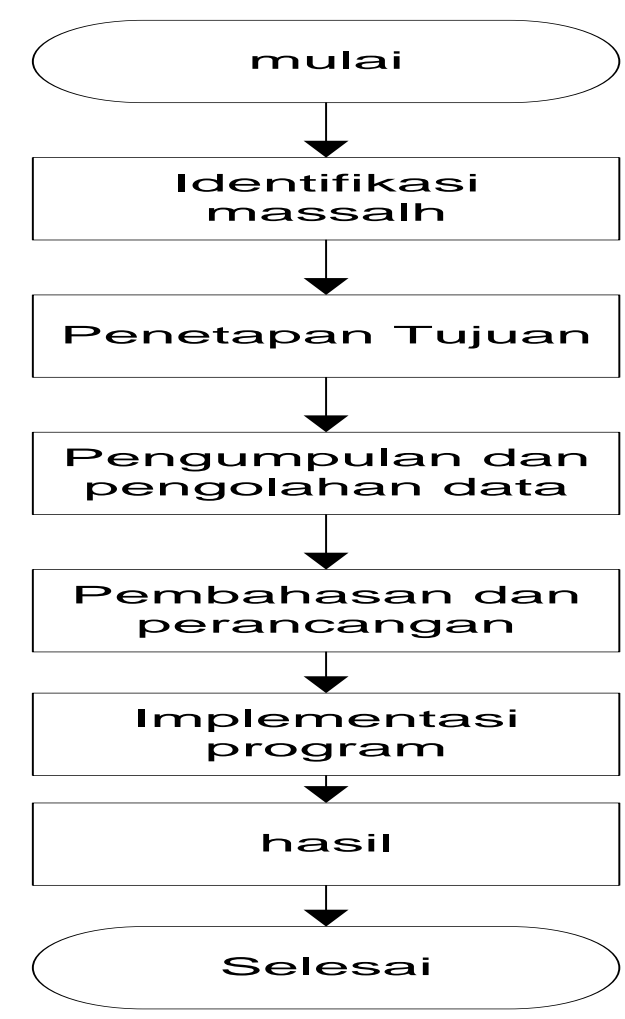

Gambar 1. Alur Analisis 


\section{CUSTOMER RELATION MANAGEMENT (CRM)}

Defenisi CRM menurut beberapa ahli antara lain, Customer Relationship Management merupakan strategi yang diimplementasikan secara luas untuk mengatur hubungan antara perusahaan dengan pelanggan, dan calon pelanggan. Customer Relationship Management sebagai suatu proses pengumpulan informasi yang akan meningkatkan pemahaman terhadap bagaimana mengelola hubungan organisasi dengan pelanggannya(Zikmund dan Gilbert, 2003) [2].

CRM didefinisikan sebagai integrasi dari strategi penjualan, pemasaran, dan pelayanan yang terkoordinasi. Ada tiga tahapan CRM, yaitu(Kalakota dan Robinson 2001) [7].

1. Mendapatkan pelanggan baru (acquire), Pelanggan baru didapatkan dengan memberikan kemudahan pengaksesan informasi, inovasi baru, dan pelayanan yang menarik.

2. Meningkatkan hubungan dengan pelanggan yang telah ada (enhance), Perusahaan berusaha menjalin hubungan dengan pelanggan melalui pemberian pelayanan yang baik terhadap pelanggannya (customer service). Penerapan cross selling atau up selling pada tahap kedua dapat meningkatkan pendapatan perusahaan dan mengurangi biaya untuk memperoleh pelanggan (reduce cost).

3. Mempertahankan pelanggan (retain), Tahap ini merupakan usaha mendapatkan loyalitas pelanggan dengan mendengarkan pelanggan dan berusaha memenuhi keinginan pelanggan.

4. Definisi menurut Laudon dan Traver, CRM menyimpan informasi pelanggan dan merekam seluruh kontak yang terjadi antara pelanggan dan perusahaan, serta membuat profil pelanggan untuk staf perusahaan yang memerlukan informasi tentang pelanggan tersebut.

5. Definisi menurut Kotler, CRM mendukung suatu perusahaan untuk menyediakan pelayanan kepada pelanggan secara real time dan menjalin hubungan dengan tiap pelanggan melalui penggunaan informasi tentang pelanggan (Kotler, 2003)[7].

\section{KLASIFIKASI CRM}

Klasifikasi CRM terbagi atas dua bagian, antara lain:

1. CRM Operasional dikenal sebagai "front office" perusahaan. Aplikasi CRM ini berperan dalam interaksi dengan pelanggan. CRM Operasional mencakup proses otomatisasi yang terintegrasi dari keseluruhan proses bisnis, seperti otomatisasi pemasaran, penjualan, dan pelayanan. Salah satu penerapan CRM yang termasuk dalam kategori operasional CRM adalah dalam bentuk aplikasi web. Melalui web, suatu perusahaan dapat memberikan pelayanan kepada pelanggan. Beberapa contoh pelayanan yang diberikan melalui web, diantaranya (Greenberg 2002 dalam Turban et al. 2004):

a) Menyediakan pencarian produk. Pelanggan sering kali mengalami kesulitan dalam mencari produk yang mereka inginkan, karena itu diperlukan fasilitas search

b) Menyediakan produk atau pelayanan gratis, sesuatu yang dapat menarik pelanggan untuk mengunjungi web adalah tersedianya produk atau pelayanan gratis

c) Menyediakan pelayanan atau informasi tentang penggunaan produk

d) Menyediakan pemesanan on line

e) Menyediakan fasilitas informasi status pemesanan

2. CRM Analitik dikenal sebagai "back office" perusahaan. Aplikasi CRM ini berperan dalam memahami kebutuhan pelanggan. CRM Analitik berperan dalam melaksanakan analisis pelanggan dan pasar, seperti analisis trend pasar dan analisis perilaku pelanggan. Data yang digunakan pada CRM Analitik adalah data yang berasal dari CRM Operasional (Greenberg, 2002)[3]. 
Keuntungan Penggunaan CRM adalah servis yang lebih cepat, mengurangi harga, memperbesar keuntungan, mempunyai rasa memiliki, meningkatkan koordinasi tim, tingkat kepuasan pelanggan menjadi lebih tinggi, meningkatkan loyalitas pelanggan (Widjaja, 2000)[14].

\section{SIKLUS CRM}

Tiga fase siklus pelanggan dari CRM adalah akuisisi pelanggan, peningkatan pelayanan kepada pelanggan dan mempertahankan pelanggan. Masing-masing dari fase ini mempunyai pengaruh terhadap hubungan dengan pelanggan, dengan tujuan untuk membuat hubungan yang lebih dekat dengan pelanggan, berikut merupakan gambar siklus CRM adalah sebagai berikut:

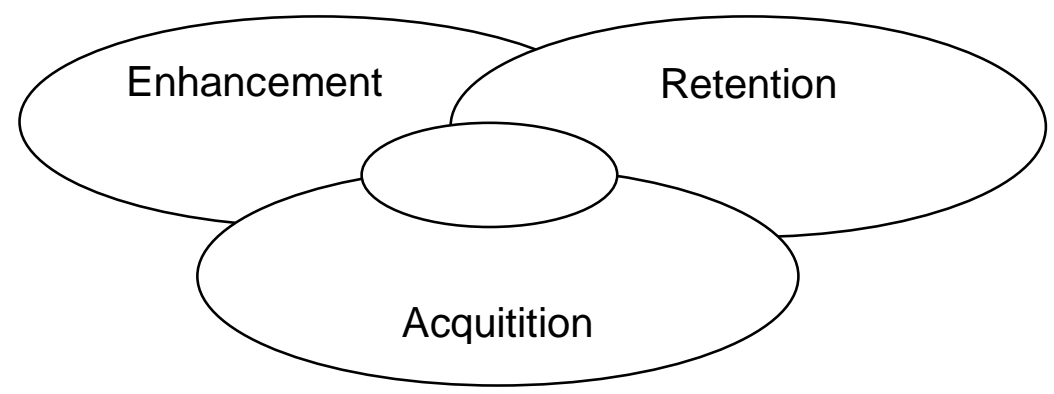

\section{Gambar 2 Siklus CRM}

Fase - fase CRM dan aktifitas utamanya sebagai berikut :

a) Accquitition

1. Penawaran produk yang beragam yang disesuaikan dengan kebutuhan pelanggan

2. Melakukan penawaran dengan sebaik-baiknya berdasarkan basis pengetahuan terhadap pelanggan

3. Memberikan pelayanan yang memuaskan dan memberikan tanggapan secara proaktif

b) Enhancement

1. Meningkatkan penjualan produk dan melakukan cross-sell

2. Meningkatkan penjualan terhadap masing masing pelanggan.

c) Retention

1. Memberdayakan basis pengetahuan tentang pelanggan untuk membangun pelayanan yang adaptif

2. Memberikan penawaran produk baru yang sesuai dengan kebutuhan pelanggan

3. Memberikan motivasi incentif kepada SDM untuk melakukan pemeliharaan pelanggan dan melakukan win back pelanggan churn.

\section{PENDEKATAN IMPLEMENTASI CRM}

Ada dua macam pendekatan implementasi CRM yaitu :

Pendekatan Technology-based Relationship: yaitu mekanisme membangun hubungan pelanggan melalui pemanfaatan kemampuan teknologi informasi dan proses bisnis yang efisien.

Beberapa alternatif solusi terkait dengan pendekatan ini yaitu:

a) Pemanfaatan teknologi untuk membangun aplikasi customer.

b) Pemanfaatan teknologi untuk membangun aplikasi billing.

c) Pemanfaatan teknologi untuk membangun aplikasi product menagement.

d) Pemanfaatan teknologi untuk membangun aplikasi customized pricing dan diskon.

e) Pemanfaatan teknologi untuk membangun aplikasi business intelligence.

Pendekatan Brand-based Relationship: yaitu mekanisme membangun hubungan pelanggan melalui pemanfaatan konsep branding melalui implementasi corporateidentify dan atau product planning. 
Beberapa alternatif solusi terkait dengan pendekatan ini yaitu:

a) Program promosi

b) Program sponsorship.

c) Program penggelaran produk-produk.

\section{TAHAPAN CRM}

Ada tiga tahapan CRM, yaitu (Kalakota dan Robinson 2001)[7].

1. Mendapatkan pelanggan baru (acquire). Pelanggan baru didapatkan dengan memberikan kemudahan pengaksesan informasi, inovasi baru, dan pelayanan yang menarik.

2. Meningkatkan hubungan dengan pelanggan yang telah ada (enhance). Perusahaan berusaha menjalin hubungan dengan pelanggan melalui pemberian pelayanan yang baik terhadap pelanggannya (customer service). Penerapan cross selling atau up selling pada tahap kedua dapat meningkatkan pendapatan perusahaan dan mengurangi biaya untuk memperoleh pelanggan (reduce cost).

3. Mempertahankan pelanggan (retain). Tahap ini merupakan usaha mendapatkan loyalitas pelanggan dengan mendengarkan pelanggan dan berusaha memenuhi keinginan pelanggan.

\section{FUNGSI-FUNGSI DALAM CRM}

Sebuah sistem CRM harus bisa menjalankan fungsi:

1. Mengidentifikasi faktor-faktor yang penting bagi pelanggan.

2. Mengusung falsafah customer-oriented (customer centric)

3. Mengadopsi pengukuran berdasarkan sudut pandang pelanggan

4. Membangun proses ujung ke ujung dalam melayani pelanggan

5. Menyediakan dukungan pelanggan yang sempurna

6. Menangani keluhan/komplain pelanggan

7. Mencatat dan mengikuti semua aspek dalam penjualan

8. Membuat informasi holistik tentang informasi layanan dan penjualan dari pelanggan

Setelah era digital yang selalu menggunakan "e-" di depan semua kata seperti e-commerce, e-book, e-sales, e-mail, dan sebagainya, Customer Relationship Management (CRM) merupakan akronim atau singkatan yang paling populer di kalangan orang-orang sales dan marketing. Dalam bahasa Indonesia CRM diartikan sebagai Manajemen Hubungan Pelanggan (MHP). Telaah per katanya adalah sebagai berikut:

1. Pelanggan atau customer, dalam kamus Bahasa Inggris artinya adalah seseorang yang berulang kali atau secara teratur melakukan pembelian kepada seorang pedagang. Jadi pelanggan adalah orangnya (dalam definisi ini tidak disinggung tentang kepuasan, mahal murahnya pembelian, dan lain-lain).

2. Hubungan atau relationship adalah bentuk komunikasi dua arah antara pembeli dan penjual.

3. Manajemen artinya pengelolaan (secara luas tanpa perlu menjabarkan detail bagaimana mengelola sesuatu). Jadi penggabungan kata customer, relationship, dan manajemen (CRM) mempunyai arti sebagai pengelolaan hubungan dua arah antara suatu perusahaan dengan orang yang menjadi pelanggan di perusahaan tersebut.

\section{FOKUS BISNIS PADA CRM}

Mengelola berbagai hubungan pelanggan melibatkan dua tujuan yang saling berkaitan : pertama, memberi organisasi dan semua karyawannya yang berhadapan dengan pelanggan, satu pelanggan lengkap tentang setiap pelanggan di setiap hal dan di lintas semua saluran; dan, kedua, memberi pelanggan satu pandangan lengkap tentang perusahaan dan saluran-salurannya yang luas. CRM menggunakan teknologi informasi untuk membuat sistem lintas fungsi perusahaaan yang mengintegrasikan dan mengotomatisasi banyak proses layanan pada pelanggan dalam penjualan, pemasaran, dan layanan pelanggan yang berinteraksi dengan pelanggan perusahaan. Sistem CRM juga menciptakan kerangka kerja TI software serta database yang dijalankan melalui Web, yang mengintegrasikan proses-proses ini dengan operasi bisnis perusahaan lainnya, dan mendukung kerja sama antara perusahaan dengan para pelanggan, serta mitranya.(O’Brien, 2005)[11]. 


\section{PEMASARAN DAN PEMENUHAN PESANAN PADA CRM}

Sistem CRM membantu para praktisi pemasaran menyelesaikan kampanye pemasaran langsung dengan mengotomatisasi tugas-tugas seperti pengkualifikasian pemasaran pada sasaran, dan penjadwalan serta penelusuran pengiriman surat pemasaran langsung. Kemudian, software CRM akan membantu para praktisi pemasaran untuk menangkap dan mengelola data respons pelanggn dan calon pelanggan di database CRM, serta menganalisis nilai pelanggan dan nilai bisnis dari kampanye pemasaran langsung perusahaan. CRM juga membantu dalam pemenuhan respons calon pelanggan serta pelanggan dengan secara tepat menjadwalkan kontak penjualan serta memberi informasi yang tepat atas produk dan jasa bagi mereka, sementara sambil menangkap informasi yang relevan untuk disimpan ke dalam database CRM. (O'Brien, 2005)[11].

\section{LAYANAN DAN DUKUNGAN UNTUK PELANGGAN}

Sistem CRM memberi para staf penjualan alat software dan akses real-time ke database umum pelanggan yang dapat dibagi bersama dengan para praktisi penjualan dan pemasaran. CRM membantu para manajer layanan pelanggan membuat, menetapkan, dan mengelola berbagai permintaan atas layanan dari pelanggan. Software call center mengirimkan semua panggilan ke para staf dukungan untuk pelanggan berdasarkan pada keahlian serta otoritas mereka untuk menangani permintaan layanan tertentu. Software help desk membantu para staf layanan untuk pelanggan membantu para pelanggan yang memiliki masalah dengan suatu produk atau jasa, dengan memberi data layanan dan saran yang relevan untuk mengatasi masalah tersebut. Layanan mandiri berbasis web memungkinkan para pelanggan mengakses dengan mudah informasi pendukung pribadi di situs Web perusahaan, dengan tetap memberi mereka pilihan untuk menerima bantuan lebih jauh secara online atau melalui telepon dari personel layanan pelanggan. $\left(\mathrm{O}^{\prime}\right.$ Brien, 2005)[11].

\section{PENERAPAN STRATEGI CRM}

Tujuan dari strategi CRM adalah untuk membentuk interaksi antara perusahaan dan pelanggannya dengan cara memaksimalkan nilai hidup pelanggan untuk perusahaan. Hal ini juga mencerminkan filosofi bahwa tidak semua pelanggan diciptakan sama. Berikut merupakan gambar komponen strategi CRM:

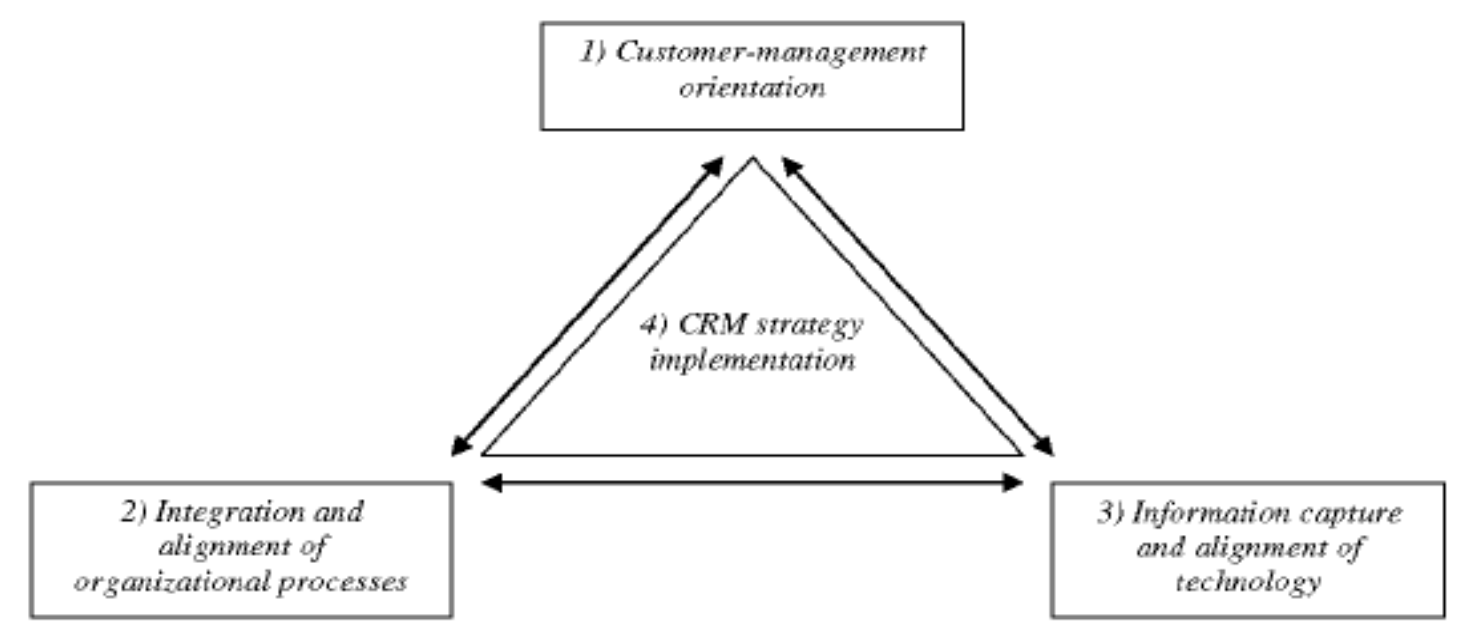

\section{Gambar 3. Komponen Strategi CRM}


Strategi CRM membutuhkan empat komponen :

1. Customer-management orientation, Customer-management orientation mencakup sekumpulan nilai-nilai perusahaan serta strategi dan aksinya dalam mengimplementasikan customer management principles

2. Integration and alignment of organizational processes, Integration and alignment of organizational processes dikelola dengan memahami nilai yang akan diberikan pada pelanggan yang sudah ditargetkan sesuai dengan prosesnya. Komponen ini dapat digunakan untuk menjelaskan dan merancang proses organisasinya.

3. Information capture and alignment of technology, Information capture and alignment of technology dikarakteristikan oleh kemampuan dalam mentransfer data menjadi dalam bentuk informasi

4. CRM strategy implementation, Pengimplementasian CRM dalam proses dan aktivitas dibutuhkan untuk menyukseskan strategi CRM.

\section{ANALISA REGRESI}

Analisis regresi (regression analysis) merupakan suatu teknik untuk membangun persamaan dan menggunakan persamaan tersebut untuk membuat perkiraan (prediction). Dengan demikian, analisis regresi sering disebut sebagai analisis prediksi. Karena merupakan prediksi, maka nilai prediksi tidak selalu tetap dengan nilai riilnya, semakin kecil tingkat penyimpangan antara nilai prediksi dengan nilai riilnya, maka semakin tepat persamaan regresinya. Analisis regresi mempelajari hubungan yang diperoleh dinyatakan dalam persamaan matematika yang menyatakan hubungan fungsional antara variabel-variabel. Hubungan fungsional antara satu variabel prediktor dengan satu variabel kriterium disebut analisis regresi sederhana (tunggal), sedangkan hubungan fungsional yang lebih dari satu variabel disebut analisis regresi ganda. Sehingga dapat didefinisikan bahwa: Analisis regresi adalah metode statistik yang digunakan untuk menentukan kemungkinan hubungan antara variabel-variabel. Analisis regresi adalah suatu proses memperkirakan secara sistematis tentang apa yang paling mungkin terjadi dimasa yang akan datang berdasarkan informasi yang sekarang dimiliki agar memperkecil kesalahan. Regresi merupakan suatu alat ukur yang juga dapat digunakan untuk mengukur ada atau tidaknya korelasi antarvariabel. Jika kita memiliki dua buah variabel atau lebih maka sudah selayaknya apabila kita ingin mempelajari bagaimana variabel-variabel itu berhubungan atau dapat diramalkan. Analisis regresi dapat juga diartikan sebagai usaha memprediksi perubahan. Perubahan nilai suatu variabel dapat disebabkan karena adanya perubahan pada variabel-variabel lain yang mempengaruhinya. Analisis regresi linear berganda sebenarnya sama dengan analisis regresi linear sederhana, hanya variabel bebasnya lebih dari satu buah. Persamaan umumnya adalah:

$\mathrm{Y}=\mathrm{a}+\mathrm{b}_{1} \mathrm{X}_{1}+\mathrm{b}_{2} \mathrm{X}_{2}+\ldots .+\mathrm{b}_{\mathrm{n}} \mathrm{X}_{\mathrm{n}}$.

Dengan $\mathrm{Y}$ adalah variabel bebas, dan $\mathrm{X}$ adalah variabel-variabel bebas, a adalah konstanta (intersept) dan $\mathrm{b}$ adalah koefisien regresi pada masing-masing variabel bebas.[9]

\section{PEMBAHASAN DAN PERANCANGAN}

\section{PEMBAHASAN}

Penelitian ini mereplikasi sebagian penelitian dari Lawson et al(2004)[8]. Menguji dampak dari CRM terhadap loyalitas pelanggan yang dimoderasi oleh karakteristik website sedangkan dikarenakan berbagai kendala dan keterbatasan dalam penelitian maka peneliti mencoba menggunakan sebagian konsep dan metode dari penelitian Lawson et al yaitu untuk menguji apakah CRM yang diterapkan oleh PT Aneka susu akan berpengaruh terhadap loyalitas pelanggannya. Berdasarkan teori diatas, model penelitian CRM akan mereplikasi loyalitas pelanggan antara lain sebagai berikut: 


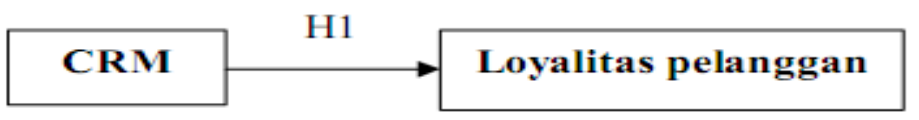

Gambar 4. Model Penelitian

\section{Regresi Linear Sederhana}

Analisis regresi linear sederhana dipergunakan untuk mengetahui pengaruh antara satu buah variabel bebas terhadap satu buah variabel terikat. Persamaan umumnya adalah: $Y=a+b$ $\mathrm{X}$.Dengan $\mathrm{Y}$ adalah variabel terikat dan $\mathrm{X}$ adalah variabel bebas. Koefisien a adalah konstanta (intercept) yang merupakan titik potong antara garis regresi dengan sumbu Y pada koordinat kartesius.

Interpretasi Output, Koefisien determinasi

Koefisien determinasi mencerminkan seberapa besar kemampuan variabel bebas dalam menjelaskan varians variabel terikatnya. Mempunyai nilai antara $0-1$ di mana nilai yang mendekati 1 berarti semakin tinggi kemampuan variabel bebas dalam menjelaskan varians variabel terikatnya.

1. Nilai thitung dan signifikansi

Nilai $\mathrm{t}$ hitung $>\mathrm{t}$ tabel berarti ada pengaruh yang signifikan antara variabel bebas terhadap variabel terikat, atau bisa juga dengan signifikansi di bawah 0,05 untuk penelitian sosial, dan untuk penelitian bursa kadang-kadang digunakan toleransi sampai dengan 0,10 .

\section{Persamaan regresi}

Sebagai ilustrasi variabel bebas: Biaya promosi dan variabel terikat: Profitabilitas (dalam juta rupiah) dan hasil analisisnya $\mathrm{Y}=1,2+0,55 \mathrm{X}$. Berarti interpretasinya:

1. Jika besarnya biaya promosi meningkat sebesar 1 juta rupiah, maka profitabilitas meningkat sebesar 0,55 juta rupiah.

2. Jika biaya promosi bernilai nol, maka profitabilitas akan bernilai 1,2 juta rupiah.

\section{Hipotesis:}

Ho $: \mathrm{b} 1=\mathrm{b} 2=0$, Promosi dan Harga tidak berpengaruh signifikan terhadap keputusan konsumen membeli susu merek "Bebelac". Ha : b1 ${ }^{1}$ b2 ${ }^{1}$ 0, Promosi dan Harga berpengaruh signifikan terhadap keputusan konsumen membeli susu merek "Bebelac".

Tabel 1 Data kasus

\begin{tabular}{|l|l|l|l|}
\hline No.Responden & Promosi (X1) & Harga(X2) & $\begin{array}{c}\text { Keputusan Konsumen } \\
(\mathbf{Y})\end{array}$ \\
\hline 1 & 10 & 7 & 23 \\
\hline 2 & 2 & 3 & 7 \\
\hline 3 & 4 & 2 & 15 \\
\hline 4 & 6 & 4 & 17 \\
\hline 5 & 8 & 6 & 23 \\
\hline 6 & 7 & 5 & 22 \\
\hline
\end{tabular}




\begin{tabular}{|l|l|l|l|}
\hline 7 & 4 & 3 & 10 \\
\hline 8 & 6 & 3 & 14 \\
\hline 9 & 7 & 4 & 20 \\
\hline 10 & 6 & 3 & 19 \\
\hline Jumlah & 60 & 40 & 170 \\
\hline \hline
\end{tabular}

Tabel 2 Tabel Data Pembantu

\begin{tabular}{|l|l|l|l|l|l|l|l|l|}
\hline $\begin{array}{l}\text { No. } \\
\text { Resp. }\end{array}$ & $\mathrm{X} 1$ & $\mathrm{X} 2$ & $\mathrm{Y}$ & $\mathrm{X} 1 \mathrm{Y}$ & $\mathrm{X} 2 \mathrm{Y}$ & $\mathrm{X} 1 \mathrm{X} 2$ & $\mathrm{X}_{1}{ }^{2}$ & $\mathrm{X}_{2}{ }^{2}$ \\
\hline 1 & 10 & 7 & 23 & 230 & 161 & 70 & 100 & 49 \\
\hline 2 & 2 & 3 & 7 & 14 & 21 & 6 & 4 & 9 \\
\hline 3 & 4 & 2 & 15 & 60 & 30 & 8 & 16 & 4 \\
\hline 4 & 6 & 4 & 17 & 102 & 68 & 24 & 36 & 16 \\
\hline 5 & 8 & 6 & 23 & 184 & 138 & 48 & 64 & 36 \\
\hline 6 & 7 & 5 & 22 & 154 & 110 & 35 & 35 & 25 \\
\hline 7 & 4 & 3 & 10 & 40 & 30 & 12 & 16 & 9 \\
\hline 8 & 6 & 3 & 14 & 84 & 42 & 18 & 36 & 9 \\
\hline 9 & 7 & 4 & 20 & 140 & 80 & 28 & 49 & 16 \\
\hline 10 & 6 & 3 & 19 & 114 & 57 & 18 & 36 & 9 \\
\hline Jumlah & 60 & 40 & 170 & 1122 & 737 & 267 & 406 & 182 \\
\hline
\end{tabular}

$\stackrel{a}{ } \mathrm{Y}=\mathrm{an}+\mathrm{b}_{1}+\stackrel{\circ}{\mathrm{a}} \mathrm{X}_{1}+\mathrm{b}_{2}+\stackrel{\circ}{\mathrm{a}} \mathrm{X}_{2}$

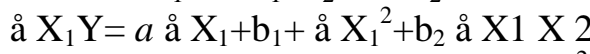

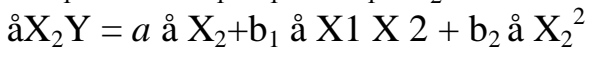

$170=10 \mathrm{a}+60 \mathrm{~b} 1+40 \mathrm{~b} 2$

$1122=60 a+406 b 1+267 b 2$

$737=40 \mathrm{a}+267 \mathrm{~b} 1+182 \mathrm{~b} 2$.

Persamaan (1) dikalikan 6, persamaan (2) dikalikan 1:

$1020=60 a+360 b 1+240 b 2$

$35163=60 a+406 b 1+267 b 2$

$-102=0 \mathrm{a}+-46 \mathrm{~b} 1+-27 \mathrm{~b} 2$

$-102=-46$ b1 -27 b2

Persamaan (1) dikalikan 4, persamaan (3) dikalikan 1:

$680=40 a+240 b 1+160 b 2$

$737=40 \mathrm{a}+267 \mathrm{~b} 1+182 \mathrm{~b} 2$

$-57=0 \mathrm{a}+-27 \mathrm{~b} 1+-22 \mathrm{~b} 2$

$-57=-27 \mathrm{~b} 1-22 \mathrm{~b} 2$.

Persamaan (4) dikalikan 27, persamaan (5) dikalikan 46:

$-2754=-1242 \mathrm{~b} 1-729 \mathrm{~b} 2$

$-2622=-1242 \mathrm{~b} 1-1012 \mathrm{~b} 2$

$-132=0 \mathrm{~b} 1+283 \mathrm{~b} 2$

b2 $=-132: 283=-0,466$

Harga b2 dimasukkan ke dalam salah satu persamaan (4) atau (5):

$-102=-46$ b1 $-27(-0,466)$

$-102=-46 b 1+12,582$

$46 \mathrm{~b} 1=114,582$

$\mathrm{b} 1=2,4909$

Harga b1 dan b2 dimasukkan ke dalam persamaan 1:

$170=10 \mathrm{a}+60(2,4909)+40(-0,466)$

$170=10 \mathrm{a}+149,454-18,640$

$10 \mathrm{a}=170-149,454+18,640$ 
$\mathrm{a}=39,186: 10=3,9186$

Jadi:

$\mathrm{a}=3,9186$

$\mathrm{b} 1=2,4909$

b2 $=-0,466$

\section{Keterangan:}

$\mathrm{a}=$ konstanta

b1 $=$ koefisien regresi $\mathrm{X} 1$

b2 = koefisien regresi X2

Persamaan regresi:

$Y=3,9186+2,4909 \mathrm{X} 1-0,466 \mathrm{X} 2$

\section{F Tabel}

Dk Pembilang $=\mathrm{k}=2$

Dk Penyebut $=\mathrm{n}-\mathrm{k}-1=10-2-1=7$

$\mathrm{F}$ tabel $=4,74$

\section{Hipotesis}

Ho : $b 1=b 2=0$, Variabel Promosi Dan Harga Tidak Berpengaruh Signifikan Terhadap Keputusan Konsumen Membeli susu "Bebelac"

Ha : b1 ${ }^{1}$ b2 ${ }^{1}$ 0, Variabel Promosi Dan Harga Berpengaruh Signifikan Terhadap Keputusan Konsumen Membeli susu Merek "Bebelac"

\section{Kriteria:}

F hitung _ $\mathrm{F}$ tabel $=$ Ho diterima

$\mathrm{F}$ hitung $>\mathrm{F}$ tabel $=$ Ho ditolak, Ha diterima

F hitung $(5,25)>F$ tabel $(4,74)=$ Ho ditolak, Ha Diterima

Jadi, dapat disimpulkan bahwa Promosi dan Harga berpengaruh signifikan terhadap keputusan konsumen membeli susu merek "bebelac".

\section{PERANCANGAN SISTEM}

Perancangan sistem adalah merancang atau mendesain suatu sistem yang baik, yang isinya adalah langkah-langkah operasi dalam proses pengolahan data dan prosedur untuk mendukung operasi sistem.

\section{USE CASE DIAGRAM}

Bisnis proses sistem yang akan dirancang digambarkan dengan usecase diagram yang terdapat pada Gambar 5.

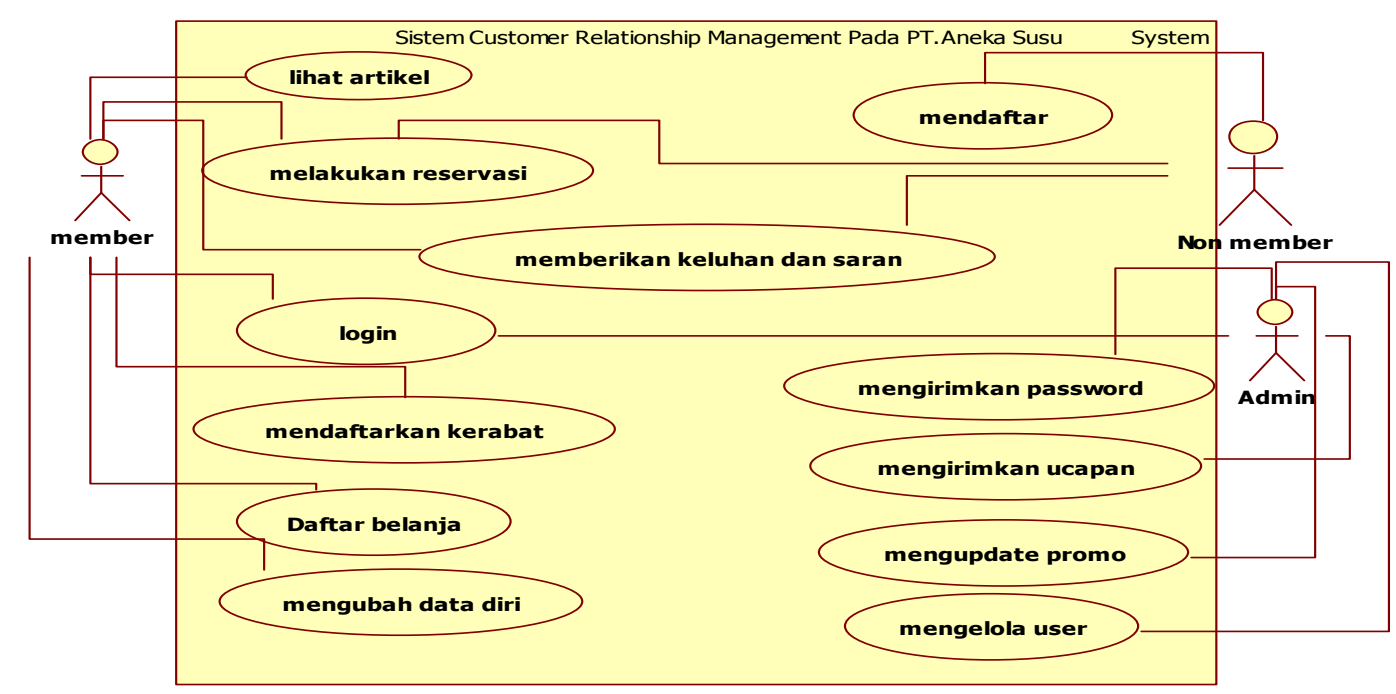

Gambar 5. Use case diagramSistem informasi CRM pada PT.Aneka Susu 


\section{CLASS DIAGRAM}

Rancangan kelas-kelas yang akan digunakan pada sistem yang akan dibangun dapat dilihat pada gambar6.

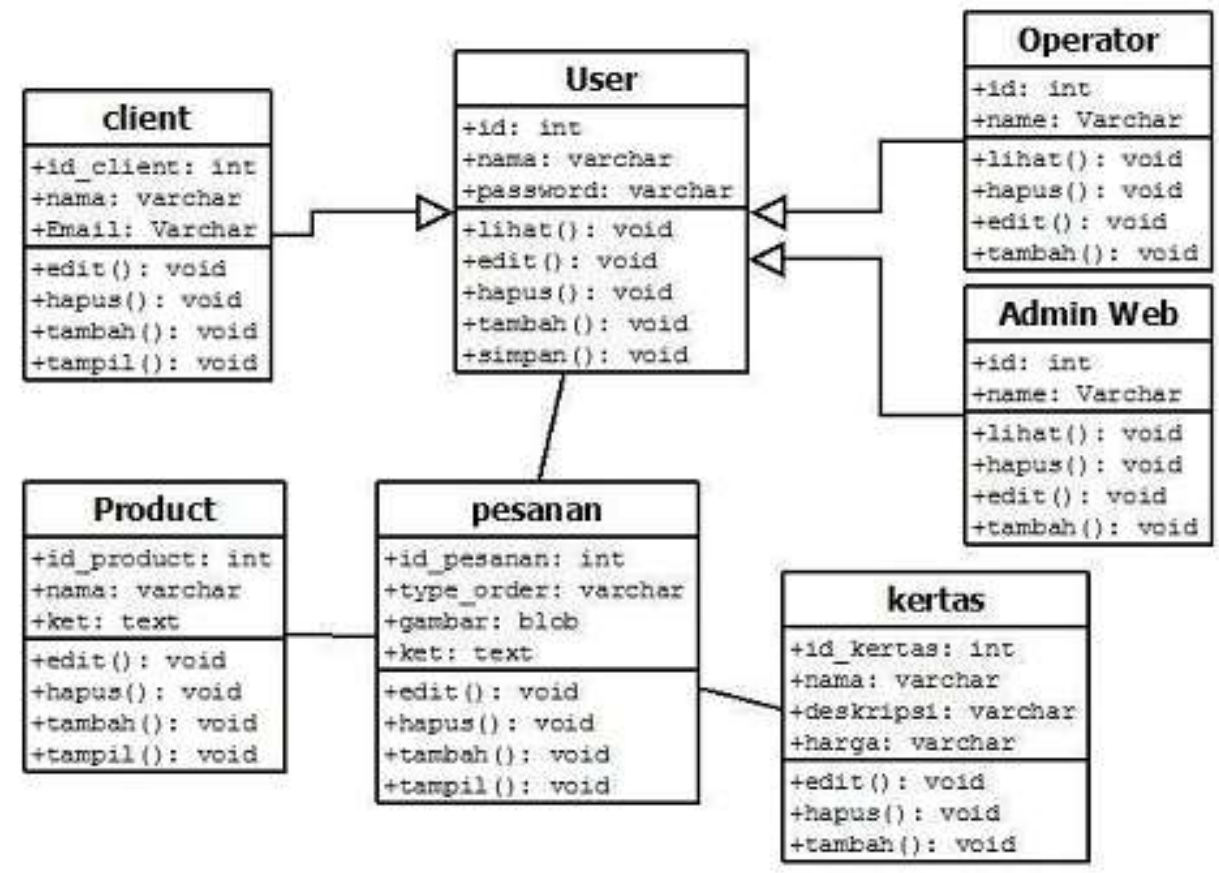

Gambar 6. Class Diagram Sistem Informasi CRM pada PT.Aneka Susu

\section{SQUENCE DIAGRAM USER}

Rangkaian kegiatan pada setiap terjadi event sistem digambarkan pada sequence diagram berikut Gambar 7. 


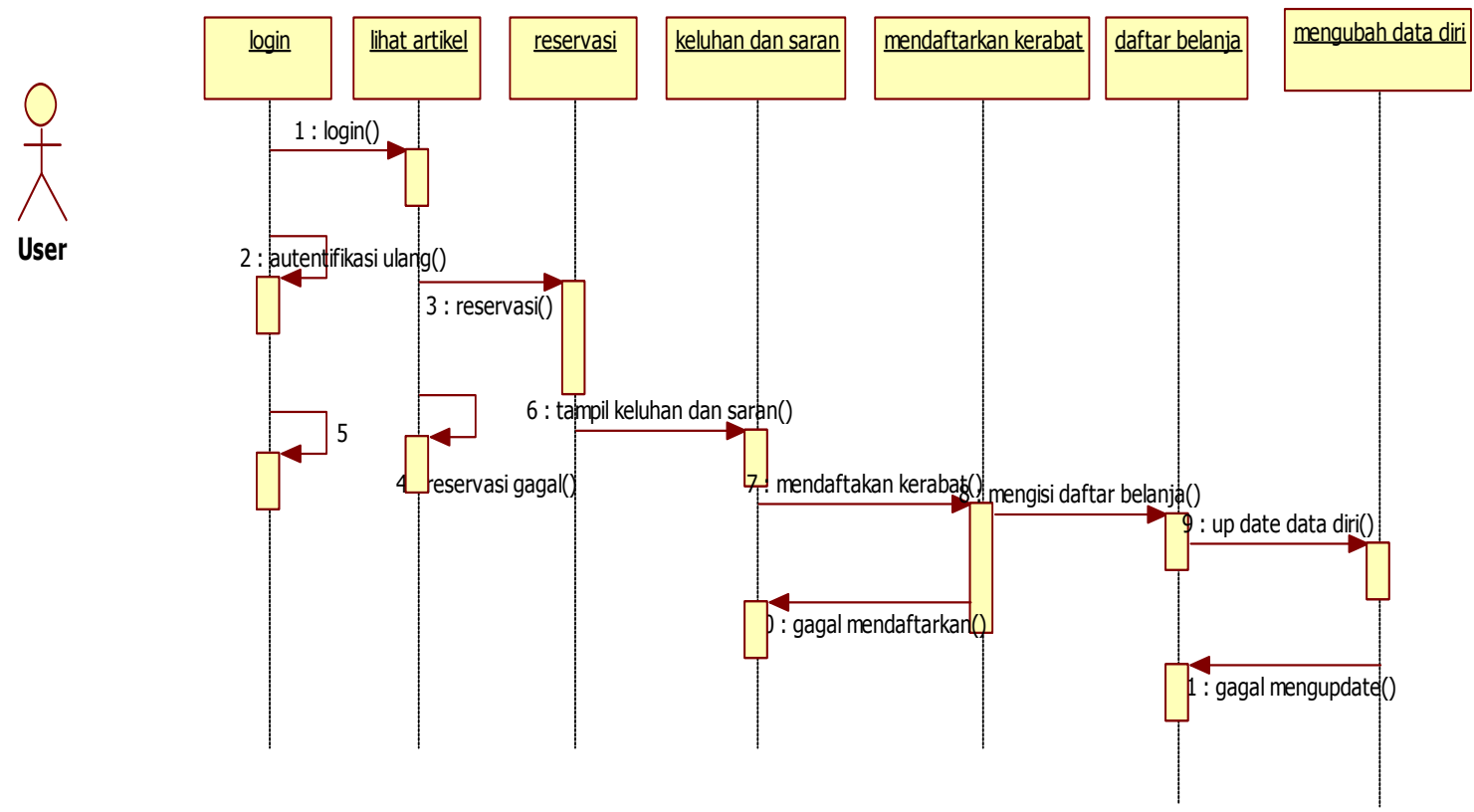

\section{Gambar 7. Sequence Diagram user}

\section{SEQUENCE DIAGRAM DATA ADMIN}

Serangkaian kerja melakukan pengolahan dataadmindapat terlihat seperti pada Gambar 8.
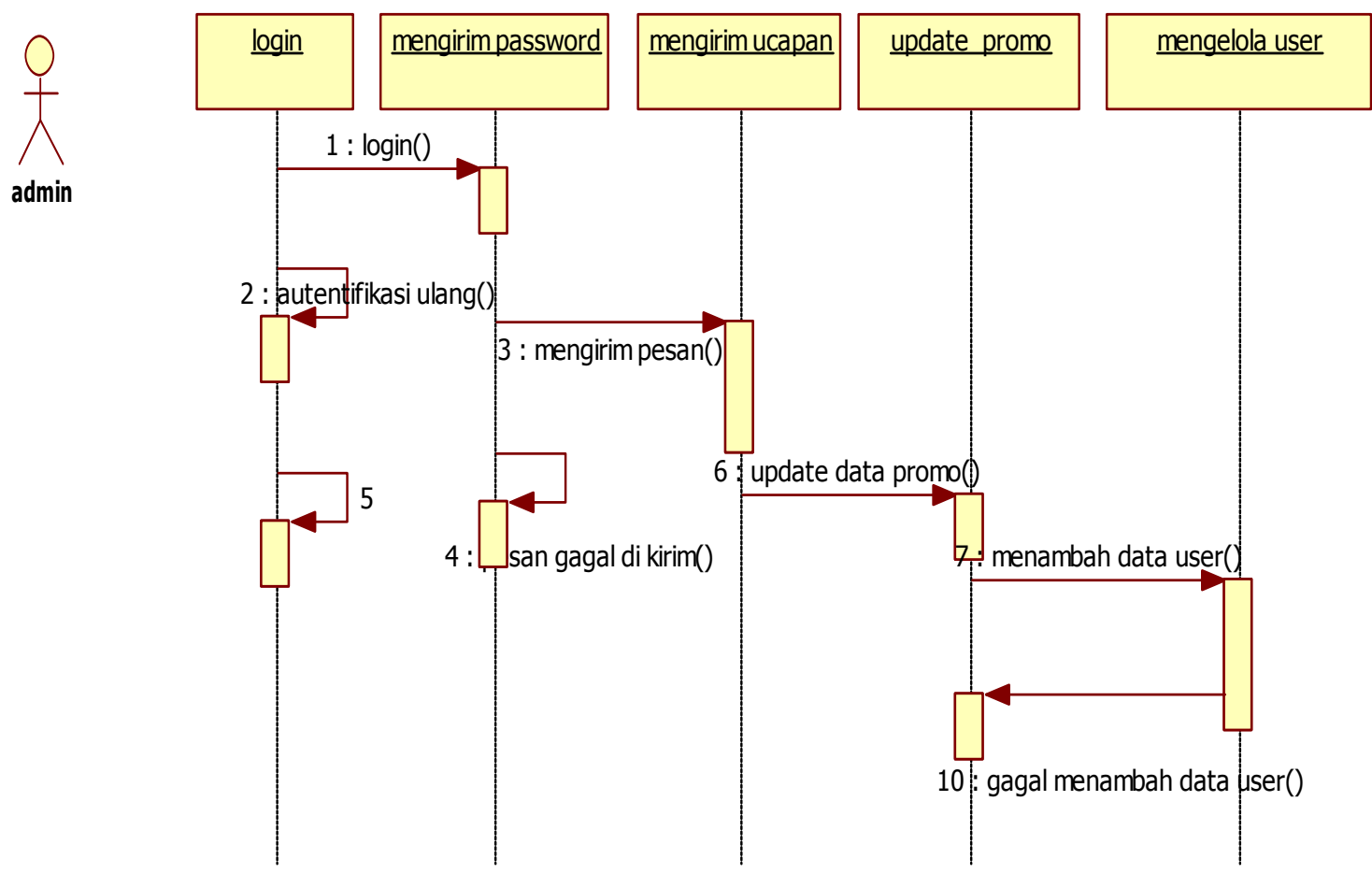

\section{Gambar 8.Sequence Diagram admin}




\section{SEQUENCE DIAGRAM DATA OPERATOR}

Serangkaian kerja melakukan pengolahan dataoperator dapat terlihat seperti pada Gambar 9.

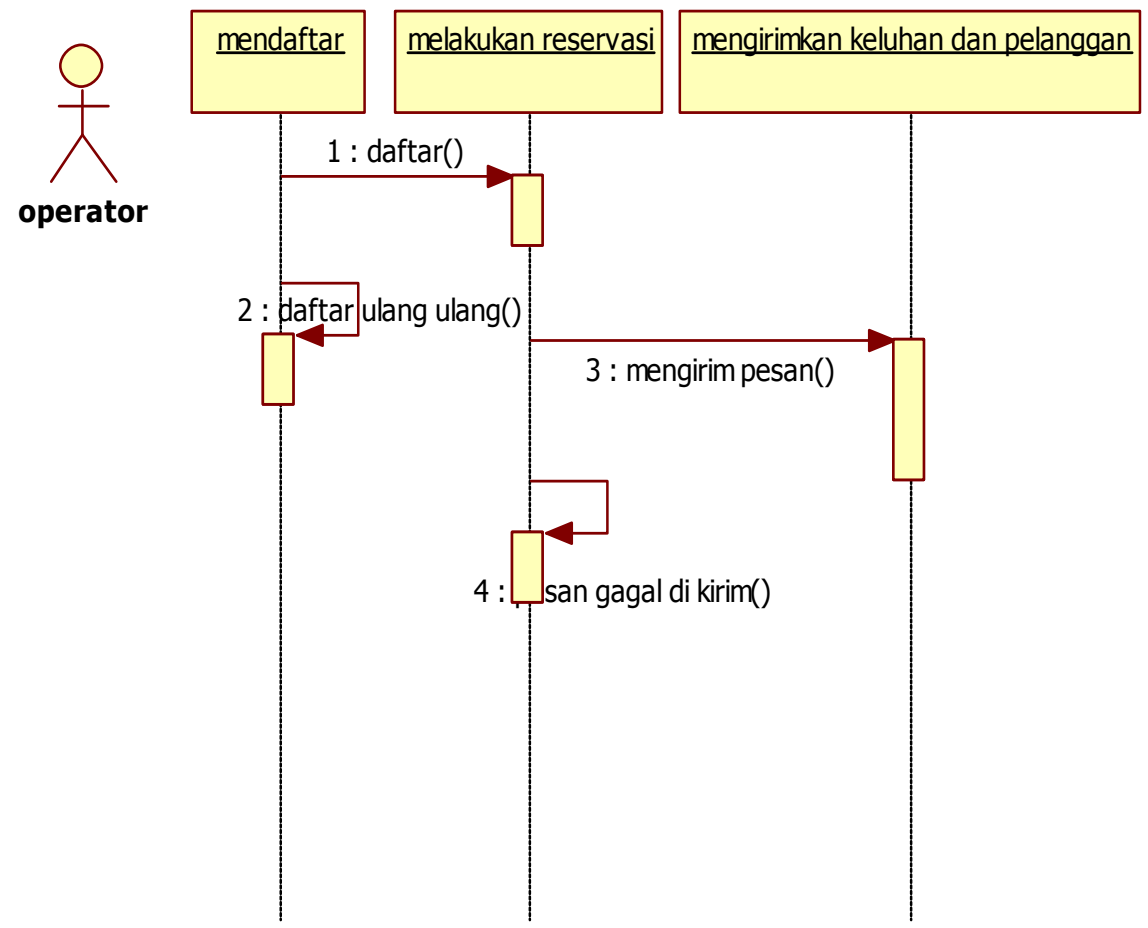

Gambar 9. Sequence Diagram operator

\section{ACTIVITY DIAGRAM LOGIN}

Aktivitas yang dilakukan untuk melakukan login pada system dapat terlihat seperti pada Gambar11.

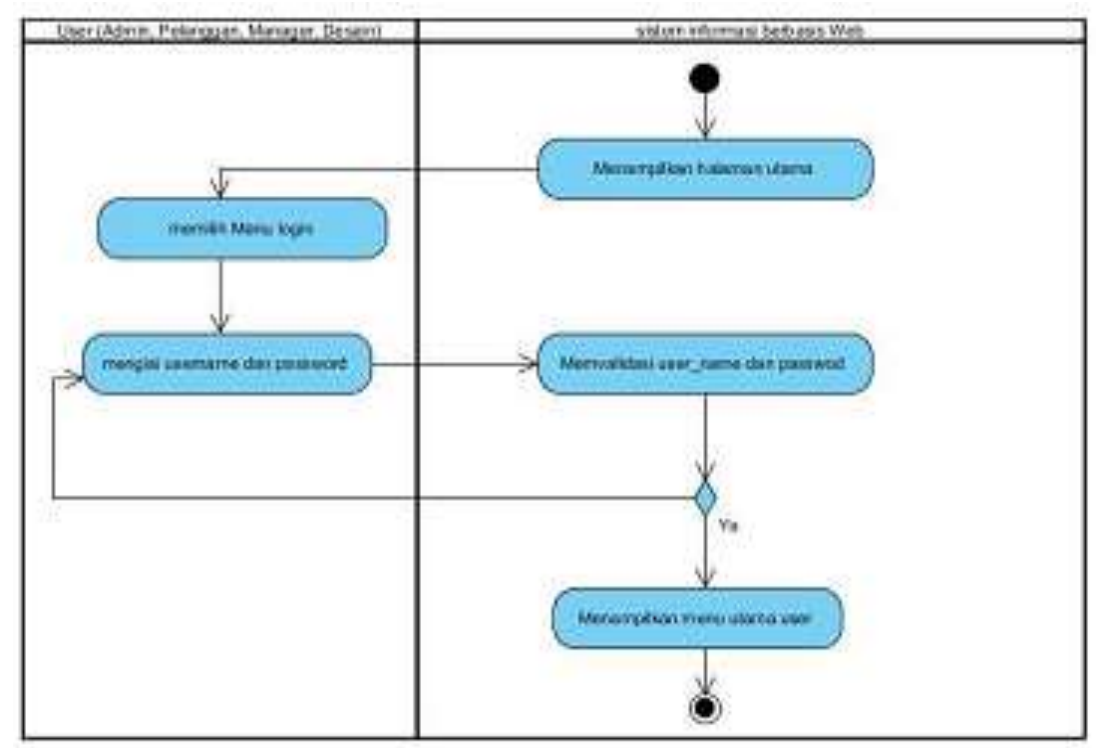

\section{Gambar 11. Activity DiagramLogin}




\section{ACTIVITY DIAGRAM DATA PENGUNJUNG}

Aktivitas yang dilakukan untuk mendata data pengunjung sistemdapat terlihat seperti pada Gambar 12.

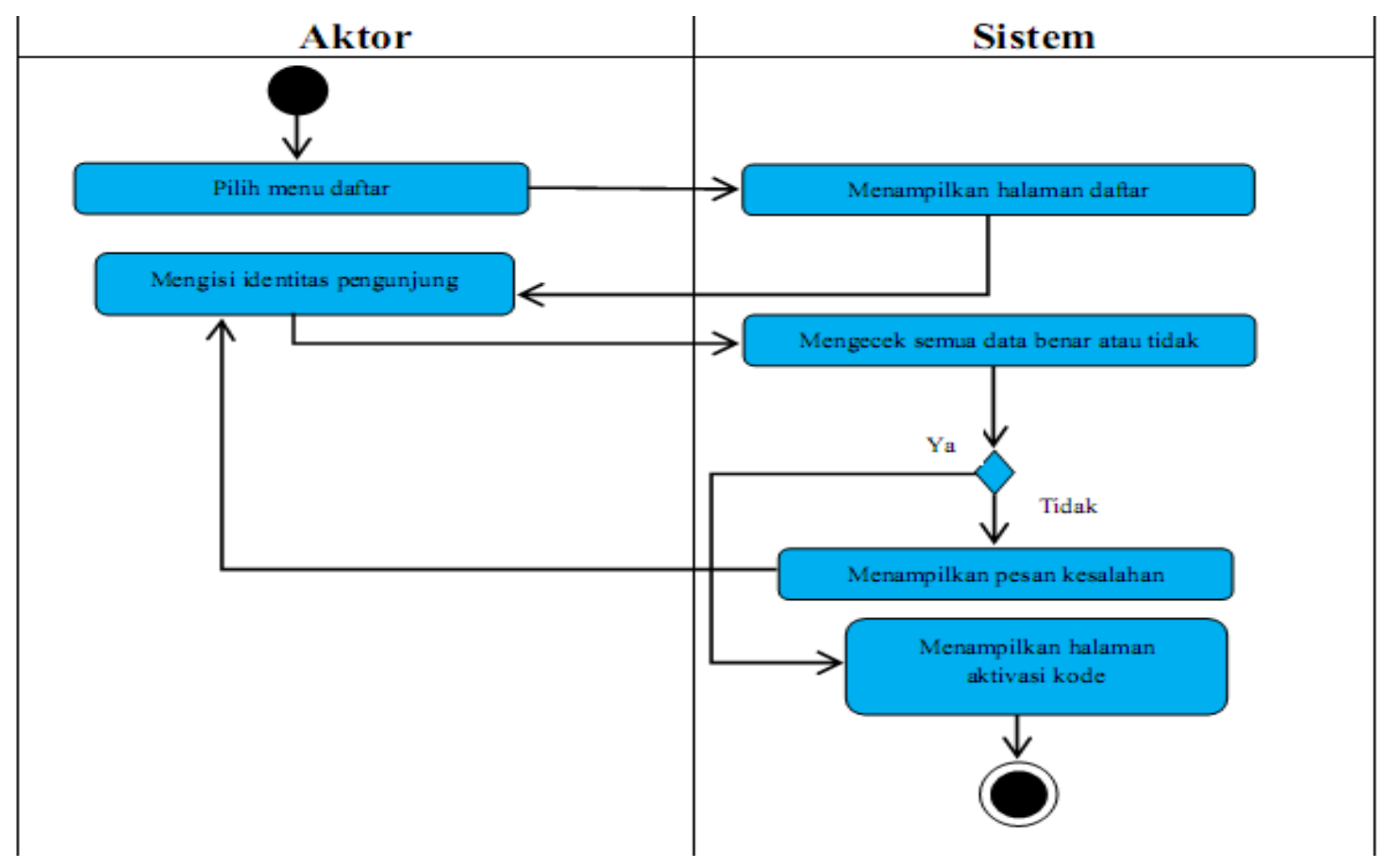

Gambar 12. Activity Diagram data pengunjung

\section{TAMPILAN HASIL FORM DATA LOGIN}

Tampilan yang disajikan oleh sistem untuk melakukan untuk bisa mengakses username dan password pada user dapat terlihat seperti pada Gambar 13.

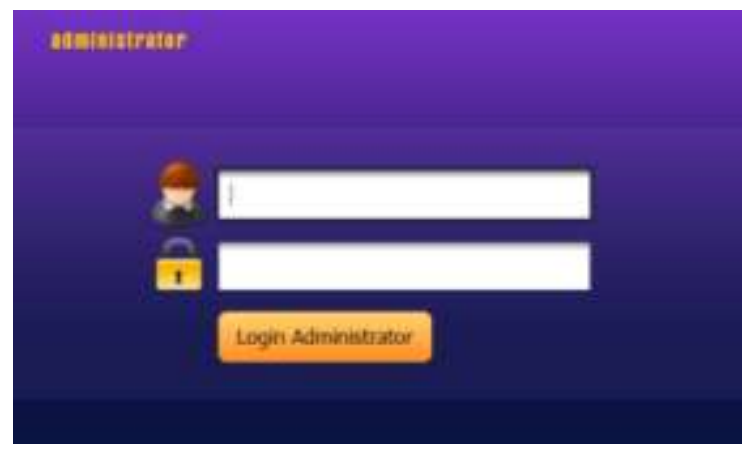

Gambar 13. Tampilanform Login

TAMPILANHASIL FORMREGISTRASI PELANGGAN

Tampilan yang disajikan oleh sistem untuk melakukan registrasi pelanggan dengan memasukkan nama dan e mail dapat terlihat seperti pada Gambar 14. 


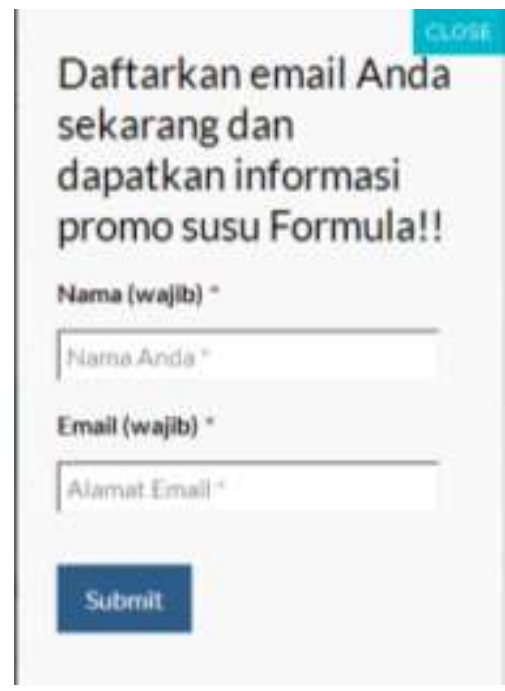

Gambar 14. Tampilan Form registrasi

TAMPILAN HASIL FORMTESTIMONY

Tampilan yang disajikan oleh sistem untuk melakukanmemberikan informasi kepada konsumen tentang masalah susu formula dapat terlihat seperti pada Gambar 15.

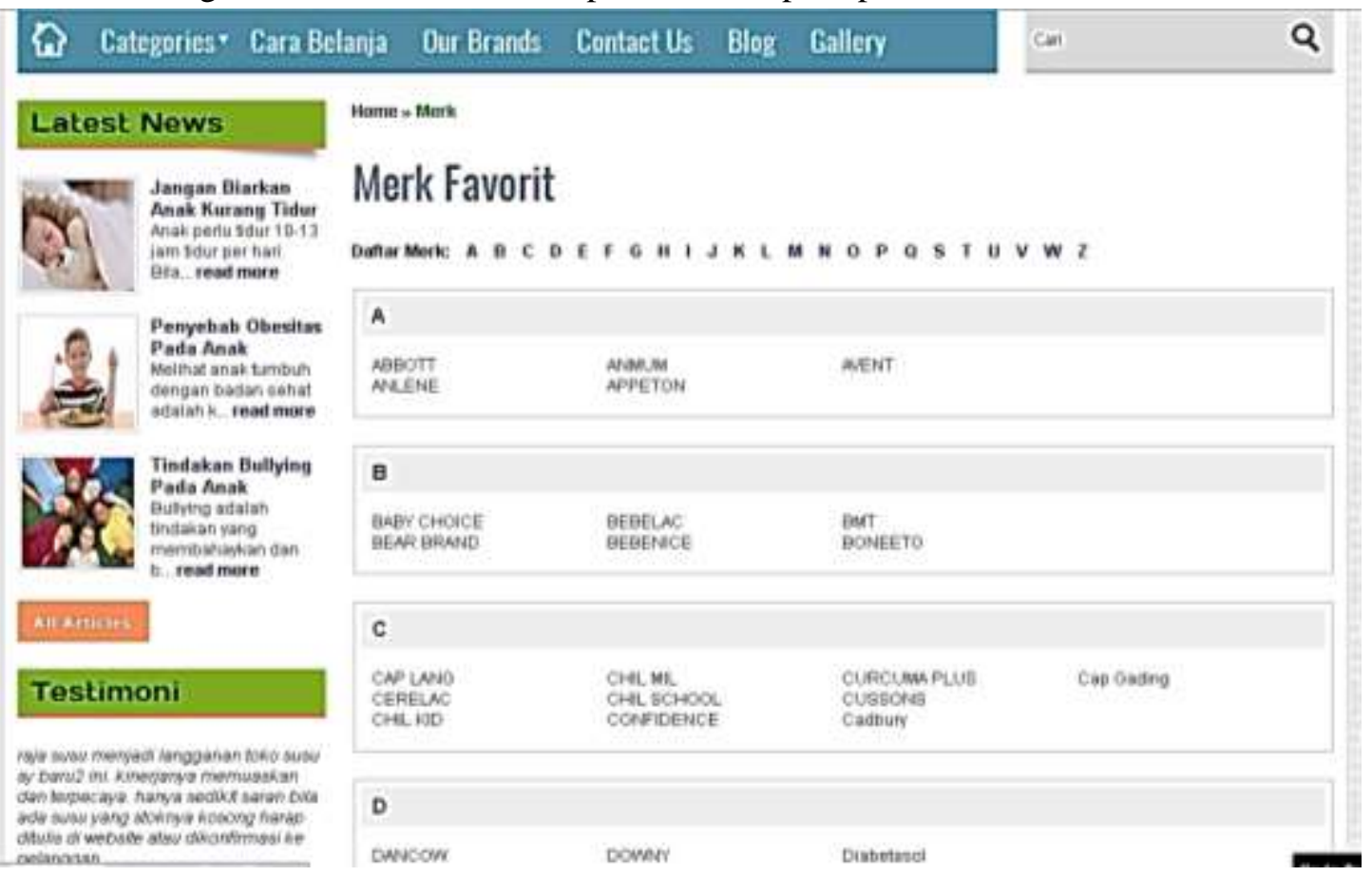

Gambar 15. Tampilan Form testimony

\section{KESIMPULAN}

Berdasarkan hasil penelitian dapat diperoleh simpulan antara lain:

CRM merupakan aplikasi yang dapat diintergrasikan ke dalam sistem informasi sebuah perusahaan dengan melakukan perubahan alur kerja, dan analisa dari respons pelanggan, CRM ini membahas aspek-aspek dari CRM yang memang sangat penting dalam meningkatkan loyalitas dari pelanggan serta keuntungan yang akan didapat oleh perusahaan. Dengan adanya penggunaan internet dan semakin majunya teknologi pada saat ini, aplikasi CRM pun berkembang dengan pesat dan diharapkan aplikasi CRM ini dapat member keuntungan yang lebih baik bagi perusahaan. 


\section{SARAN}

Saran yang disampaikan oleh penulis, antara lain:

1. Sistem yang dibuat diharapkan bisa diterapkan dan sebaiknya harus benar-benar dikaji dan dipelajari secara mendalam, sehingga didapatkan kemudahan dalam menggunakan sistem baru.

2. Dapat menambahkan sistem pembayaran online yang memang dimiliki oleh perusahaan.

3. Dapat menambahkan sistem keamanan pada CRM untuk menghindari serangan hacker.

\section{DAFTAR PUSTAKA}

[1] Brown, Stanley W. 2000. Customer Relationship Management. Singapore: John Wiley and Sons Canada, Ltd.

[2] Dadang Munandar.2011.E-Bussines.Andi.Jogjakarta

[3] Greenberg, Paul. 2002. CRM at the speed of Light: Capturing and Keeping Customers in Internet Real Time. 2nd Edition. California: McGraw-Hill Book Co.

[4] Herlawati, Prabowo Pudjo Widodo, 2007, Menggunakan UML, Informatika, Bandung.

[5] Inunk nastiti,bowo, 2012, Konsep sistem informasi, Andi Offset, Yogyakarta.

[6] Janner simarmata,iman paryudi, 2010, Basis Data, Penerbit Andi, Yogyakarta.

[7] Kalakota, Ravi dan Robinson, Marcia, 2001,E - Business 2.0 Roadmap For Success. Addison Wesley, USA

[8] Lawson et al. (2004). The Impact of Customer Relationship Management on Customer Loyalty: The Moderating Role of Web Site Characteristics. Journal of Computer-Mediated Communication

[9] M. Syafruddin, Metode Regresi Linier untuk Prediksi KebutuhanEnergi Listrik Jangka Panjang (Studi Kasus Provinsi Lampung), Jurusan Teknik ElektroUniversitas Lampung, Bandar Lampung.

[10] Nugroho, Eko, M.Si, 2008, Sistem Informasi Manajemen, Penerbit Andi, Yogyakarta.

[11] O’Brien, James.A. 2005. Introduction To Information System: Essential for The e Business Enterprise, $11^{\text {th }}$ edition. McGraw Hill, New York.

[12] Sugiarti Yuni, S.T., M.Kom. 2013, Analisis dan Perancangan UML (Unified Modelling Language) Generated VB.6, Graha Ilmu, Yogyakarta

[13] Tunggal. Amin W, 2000. Konsep Dasar Customer Relationshio Managemen,. Harvarindo, Jakarta.

[14] Widjaja, A. Tunggal. 2000, Konsep Dasar Customer Relationship Management (CRM). Harvarindo, Jakarta.

[15] Yahya, Yohannes. 2008. Pengaruh Customer Relationship Management (CRM) dalam Meningkatkan Loyalitas Pelanggan. Hal. 82-95. Jakarta: Universitas Budi Luhur. 